\title{
PLASMA CYSTATIN C AND ESTIMATES OF GLOMERULAR FILTRATION RATE USING CYSTATIN C INDEPENDENTLY DIAGNOSE ACUTE KIDNEY INJURY IN CRITICALLY ILL PATIENTS WITH SEPSIS
}

Azrina Md Ralib ${ }^{1}$, Iqbalmunawwir Ab Rashid ${ }^{1}$, Nur Aisyah Ishak ${ }^{1}$, Suhaila Nanyan ${ }^{1}$, Nur Fariza Ramly ${ }^{1}$ and Mohd Basri Mat Nor ${ }^{1}$

${ }^{1}$ Department of Anaesthesiology and Intensive Care, Kulliyyah of Medicine, International Islamic University Malaysia.

Presenter: Iqbalmunauwir Abd Rashid, driqbal.medic.iium@gmail.com

Introduction: Plasma Cystatin C (CysC) is as an early functional marker for acute kidney injury. Estimates of glomerular filtration rate using CysC (eGFR cysc $_{\text {) }}$ has been used in some clinical setting. We evaluated the utility of CysC and eGFR $\mathrm{Cysc}_{\text {c }}$ in diagnosing acute kidney injury (AKI) and predicting death in critically ill patients with sepsis.

Materials and method: This is an interim analysis of single centre, prospective observational study of critically ill patients. Inclusion criteria were patients older than 18 years old with sepsis and procalcitonin $>0.5 \mathrm{ng} / \mathrm{ml}$. Plasma creatinine and CysC were

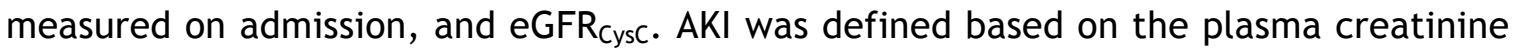
criteria of the KDIGO guideline.

Results: Thirty one patients were recruited so far, of which 13 (41.9\%) had AKI and six died. CysC were higher in patients with AKI versus No AKI $(\mathrm{p}<0.001)$, and corresponding

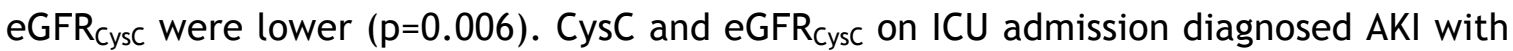
an AUC of $0.88(0.72$ to 1.00$)$, and $0.79(0.62$ to 0.96$)$, respectively. Both did not predict death (AUC 0.59 (0.31 to 0.87 ) and 0.59 (0.31 to 0.86 ), respectively). After adjusting for

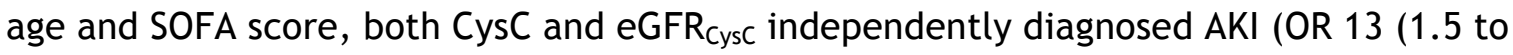
$115)$ and 1.03 (1.01 to 1.06), respectively). The ideal cut-off point for diagnosing AKI for CysC is $1.5 \mathrm{mg} / \mathrm{dl}$ (84\% sensitivity and $89 \%$ specificity) and for eGFR cysc $_{\text {as }} 77 \mathrm{ml} / \mathrm{min}(72 \%$ sensitivity and $84 \%$ specificity).

Conclusion: Plasma CysC and its estimated GFR independently diagnosed AKI in critically ill patients with sepsis. We suggest the ideal cut-off points of $1.5 \mathrm{mg} / \mathrm{dl}$ and $77 \mathrm{ml} / \mathrm{min}$ which can be used in the clinical setting in this cohort of patients. 